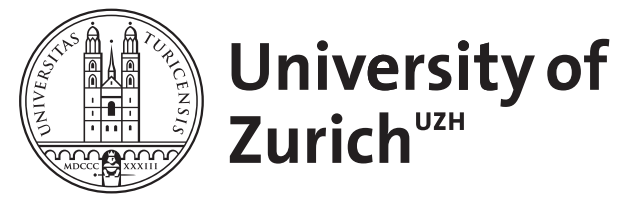
Archive

University of Zurich

University Library

Strickhofstrasse 39

CH-8057 Zurich

www.zora.uzh.ch

Year: 1989

Effect of Hydrogen on the Sintering of Pt-Black Catalyst and on its Activity in Skeletal Hydrocarbon Reactions

Paál, Zoltán ; Zimmer, Helga ; Günter, John R

DOI: https://doi.org/10.1524/zpch.1989.164.part_2.1135

Posted at the Zurich Open Repository and Archive, University of Zurich

ZORA URL: https://doi.org/10.5167/uzh-155431

Journal Article

Published Version

Originally published at:

Paál, Zoltán; Zimmer, Helga; Günter, John R (1989). Effect of Hydrogen on the Sintering of Pt-Black Catalyst and on its Activity in Skeletal Hydrocarbon Reactions. Zeitschrift für Physikalische Chemie, 164( Part $\left._{2}\right): 1135-1144$.

DOI: https://doi.org/10.1524/zpch.1989.164.part_2.1135 


\title{
Effect of Hydrogen on the Sintering of Pt-Black Catalyst and on its Activity in Skeletal Hydrocarbon Reactions*
}

\author{
Zoltán Paál, Helga Zimmer \\ Institute of Isotopes of the Hungarian Academy of Sciences, H-1525 \\ Budapest, P.O.Box 77, Hungary \\ and John R. Günter \\ Institute for Inorganic Chemistry, University of Zürich, Winterthurer- \\ strasse 190, CH-8057 Zürich, Switzerland
}

Pt-black samples were sintered in hydrogen at 473 and $633 \mathrm{~K}$. Their surface composition and electron micrographic images are discussed together with their catalytic activity in reactions of $n$-hexane and methylcyclopentane. $\mathrm{Pt}-473$ is more active in $\mathrm{n}$-hexane reactions than Pt-633; also a different hydrogen pressure sensitivity is observed. Methylcyclopentane transformations show much less differences; thus these two reactants exhibit different structure sensitivities. Hydrocarbons and hydrogen compete for active sites, the availability and hydrogen content of which may be lower on the - more carbonized Pt-633.

\section{Introduction}

Group VIII metals - in particular Pt - are typical catalysts of hydrocarbon transformations /1/. Hydrogen is a stoichiometric partner in hydrogenation reactions; however, the presence of hydrogen is also necessary for dehydrogenation reactions, e.g. in naphtha reforming where alkanes and cycloalkanes give aromatics. The Pt-containing catalysts (supported alone or together with other metallic additives on

* Presented as an Invited Lecture at the International Symposium on Metal - Hydrogen Systems, Fundamentals and Applications, Stuttgart, FRG, September 4-9, 1988. 
$\mathrm{Al}_{2} \mathrm{O}_{3}$ ) lose rapidly their activit; without hydrogen $/ 2 /$. Several such nonstoichiometric effects of hydrogen in metal catalyzed reactions have been recognized; they were summarized recently $/ 3,4 /$. Their common characteristic is that hydrogen actively participates in the formation of the catalytically active entity. In addition, hydrogen present during catalytic processes can considerably influence the actual catalytic properties.

The main problem in these hydrogen effects is the determination of how much hydrogen is present on and/or in the catalyst in various stages of its life, where it is situated and what is the likely form of its binding to the metal. No accurate answer can be given to these problems so far. Temperature-programmed desorption (TPD) studies detected three to five types of adsorbed hydrogen on Pt-black and $\mathrm{Pt} / \mathrm{SiO}_{2} / 5-8 /$. It is also debated what is the temperature at which all desorbable hydrogen leaves the catalyst. The most strongly bonded type of hydrogen may be situated in subsurface layers as demonstrated for $\mathrm{Pt} / 9 /$ and $\mathrm{Pd}$-blacks /10/; on $\mathrm{Pt}$ this hydrogen may be exchanged with hydrogen atoms of hydrocarbon reactants /9/. Maybe the penetration of hydrogen into subsurface layers is the reason why hydrogen dramatically accelerates the reconstruction of a high-surface freshly reduced $\mathrm{Pt}$-black when heated in hydrogen atmosphere between 470 and $750 \mathrm{~K} / 11 /$. A "quasi-liquid hydrogen-platinum surface overlayer" has been proposed during sintering process $/ 12 /$.

When hydrocarbons are reacted in the presence of hydrogen on $\mathrm{Pt}$-catalysts, it is more correct to regard the catalyst as a $\mathrm{Pt}-\mathrm{H}$ system". Presintering in hydrogen will determine the crystallite size $/ 11 /$, the surface morphology of $\mathrm{Pt}$, this latter being decisive in determining the character of active sites as shown by single-crystal studies $/ 13 /$. Presently we attempt at comparing two samples, presintered at 473 and $633 \mathrm{~K}$. Earlier studies reveal that the former sample has smaller crystallites $/ 11 /$, less surface carbon and oxygen impurity /14/. The chemical state of carbon corresponds to individual $\mathrm{C}$-atoms on $\mathrm{Pt}-473$ while a more polymeric carbon is present on $\mathrm{Pt}-633 / 15 /$. The former sample contains more hydrogen /16/. Surface analysis, electron microscopy and catalytic activity in model reactions as a function of the actual hydrogen pressure ("hydrogen sensitivity") will 
be reported.

\section{Experimental}

The catalysts were reduced from aqueous solution of $\mathrm{H}_{2} \mathrm{PtCl}_{6}$ by $\mathrm{HCHO}$ in the presence of $\mathrm{KOH}$, between 273 and $278 \mathrm{~K} / 17 /$. They were sintered according to a "standard thermal cycle" as described by Baird et al. /11/, at 473 and $633 \mathrm{~K}$ (Pt-433 and $\mathrm{Pt}-633$, respectively).

Secondary Ion Mass Spectrometry (SIMS) was carried out in a Balzers instrument, using $\mathrm{Ar}^{+}$primary ions $\left(3 \mathrm{keV}, 1.2 \times 10^{-5} \mathrm{~A} \mathrm{~cm}^{-2}\right)$; for more detail, see ref. $/ 16 /$.

Specimen preparation for electron microscopy was carried out by dispersing the metal powder samples in water or methanol; after ultrasonic treatment, they were dried on carbon coated grids in air. A JEOL $200 \mathrm{CX}$ microscope operated at $200 \mathrm{kV}$, equipped with an ultrahigh resolution objective pole piece was used.

Catalytic runs were carried out in a static-circulation reactor $/ 18 /$. $\mathrm{n}$-Hexane $(\mathrm{nH})$ and methylcyclopentane (MCP) were used as feeds at a pressure of 10 Torr $(1$ Torr $=0.133 \mathrm{kPa})$. Feed purity was better than $99.5 \frac{\circ}{0}$. Hydrogen pressure varied between 50 and 500 Torr. Catalytic activities are expressed as "turnover numbers", meaning the amount of product formed, molecules per surface Pt-atom per second.

\section{Results}

In agreement with previous data $/ 14-16 /$, sintering at $473 \mathrm{~K}$ resulted in some cleaning of the "as reduced" surfaces. Sintering at $633 \mathrm{~K}$ gives more surface cluster ions, presumably, owing to the polymerization of surface carbon which is bound more firmly to the metal. This is illustrated by Fig. 1. It has to be remarked that the residual hydrogen content of the catalysts decreased in the order Pt-fresh $>$ $>\mathrm{Pt}-473>\mathrm{Pt}-633 / 16 /$.

Electron micrographs show a gradual increase of particle sizes (Figure 2) as the temperature of sintering increases. These were estimated to be 5-10 nm for Pt-fresh, 20-30 nm for Pt-473 and around $100 \mathrm{~nm}$ for $\mathrm{Pt}-633$. This latter value is higher than that reported earlier $/ 11,19 /$. The high-resolution electron micrograph of $\mathrm{Pt}-473$ shows agglomeration of rounded particles with well-ordered lattice 


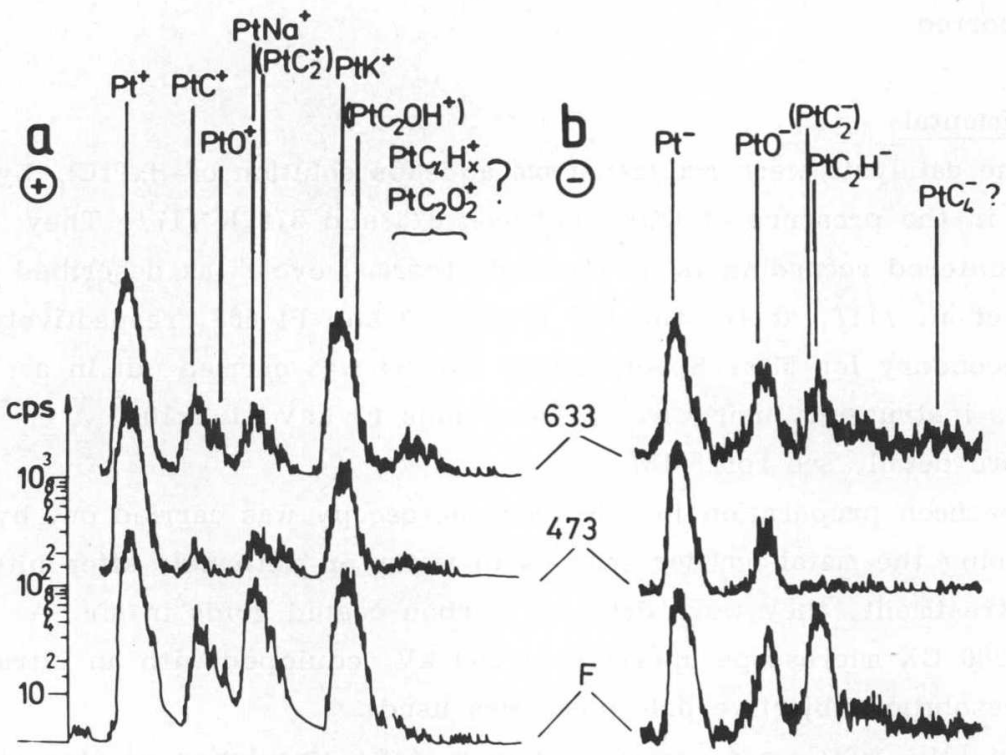

Figure 1. Secondary Ion Mass Spectra of fresh and two sintered Pt-black samples in the cluster ion range.
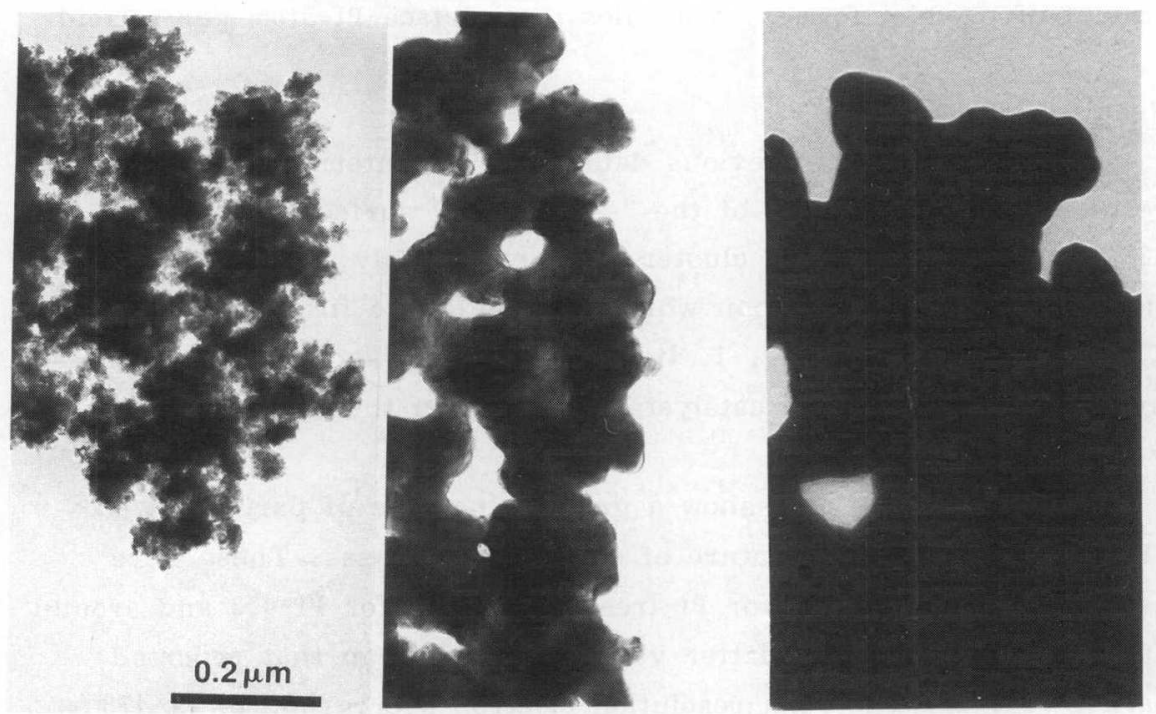

Figure 2. Electron micrographs of Pt-black samples. From left to right: Pt-fresh; Pt-473; Pt-633. 


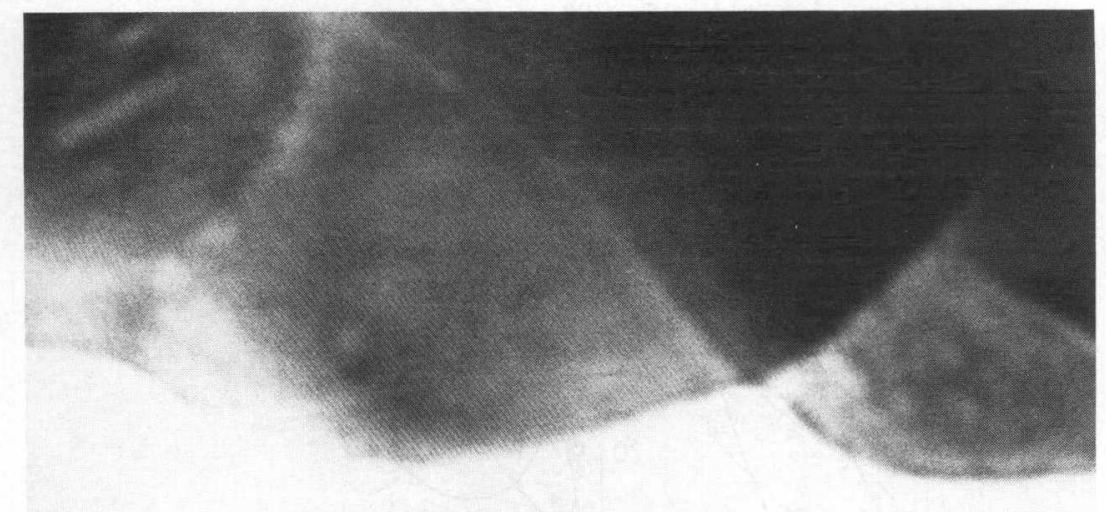

\section{$10 \mathrm{~nm}$}

Figure 3. High resolution electron micrograph of $\mathrm{Pt}-473 / 4 /$.

fringes (Figure 3). Pt-633 was not transparent for the electron beam; the rounded character of the particles can be seen in Fig. 2 .

Various reactions of $n$-hexane and methylcyclopentane require surface intermediates of various degree of dehydrogenation. The amount of surface hydrogen available controls the extent of dehydrogenation of hydrocarbons bound to the active sites and, by doing so, determines which reaction will prevail $/ 3,4 /$. That is the reason why maxima are observed in the yields of individual product classes $/ 18,20,21 /$. These maxima are not well-defined with Pt-473 (Figure 4) and appear clearly with Pt-633 (Figure 5). In the former case, the yields of isomers, fragments increase monotonically with $\mathrm{p}\left(\mathrm{H}_{2}\right)$ whereas minima are seen in MCP and benzene yields. No olefin is detected on Pt-633 while its amount decreases with $\mathrm{p}\left(\mathrm{H}_{2}\right)$ over $\mathrm{Pt}-473$. The overall activity of samples shows drastic differences: $\mathrm{Pt}-473$ is more active by about an order of magnitude. The comparison of selectivities reveal that fragmentation is most important over $\mathrm{Pt}-633$ whereas $\mathrm{Pt}-473$ is a better catalyst for nondegradative reactions, first of all, isomerization. IMCP selectivities have maxima in both cases and benzene selectivity 


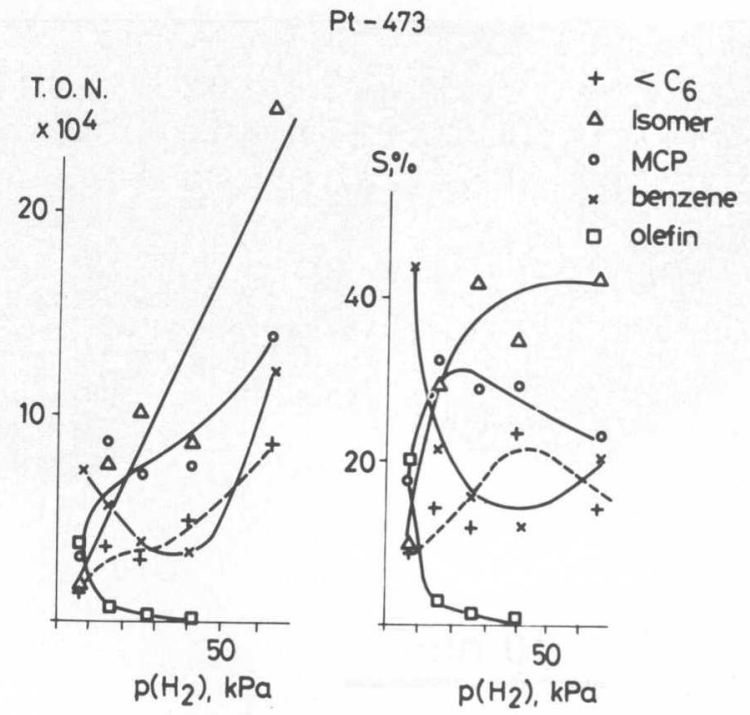

Figure 4. Activity (in terms of turnover number, T.O.N.) and selectivity, $\mathrm{S} \%$ of $\mathrm{Pt}-473$ in $\mathrm{n}$-hexane transformations, as a function of hydrogen pressure, $\mathrm{p}\left(\mathrm{H}_{2}\right) . \mathrm{T}=603 \mathrm{~K}, 0.1 \mathrm{~g}$ catalyst, $4.9 \times 10^{18}$ surface $\mathrm{Pt}$-atom $\left(\mathrm{Pt}_{\mathrm{S}}\right)$.
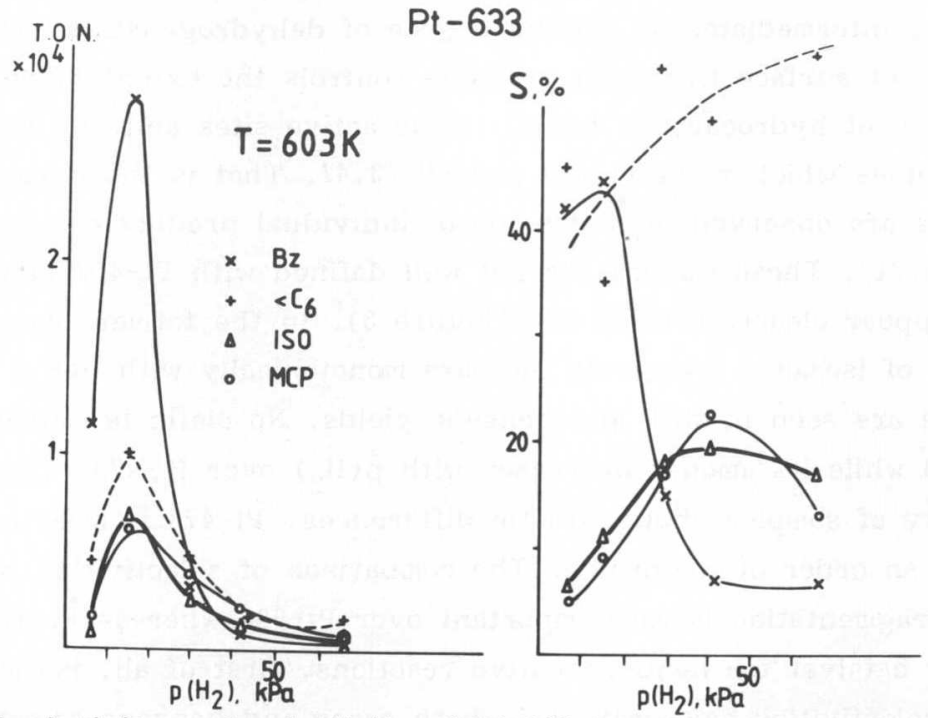

Figure 5. Activity and selectivity of Pt-633 in $\mathrm{n}$-hexane transformations. $\mathrm{T}=603 \mathrm{~K}$, catalyst : $0.1 \mathrm{~g} ; \mathrm{Pt}_{\mathrm{S}}: 2.25 \times 10^{18}$ atom. Data were taken partly from Ref. $/ 22 /$. 
decreases at higher $\mathrm{p}\left(\mathrm{H}_{2}\right)$. Again, a minimum is seen in the latter value on $\mathrm{Pt}-473$; the absolute values are also higher on that catalyst.

No differences in overall activity were observed in MCP reactions (Figure 6). Ring opening reaction prevailed over both $\mathrm{Pt}$-samples, enormously increasing with $\mathrm{p}\left(\mathrm{H}_{2}\right)$. At low $\mathrm{p}\left(\mathrm{H}_{2}\right)$, olefins were also of importance over Pt-633 and - like with n-hexane - benzene over Pt-473. Fragmentation was unimportant in both cases.

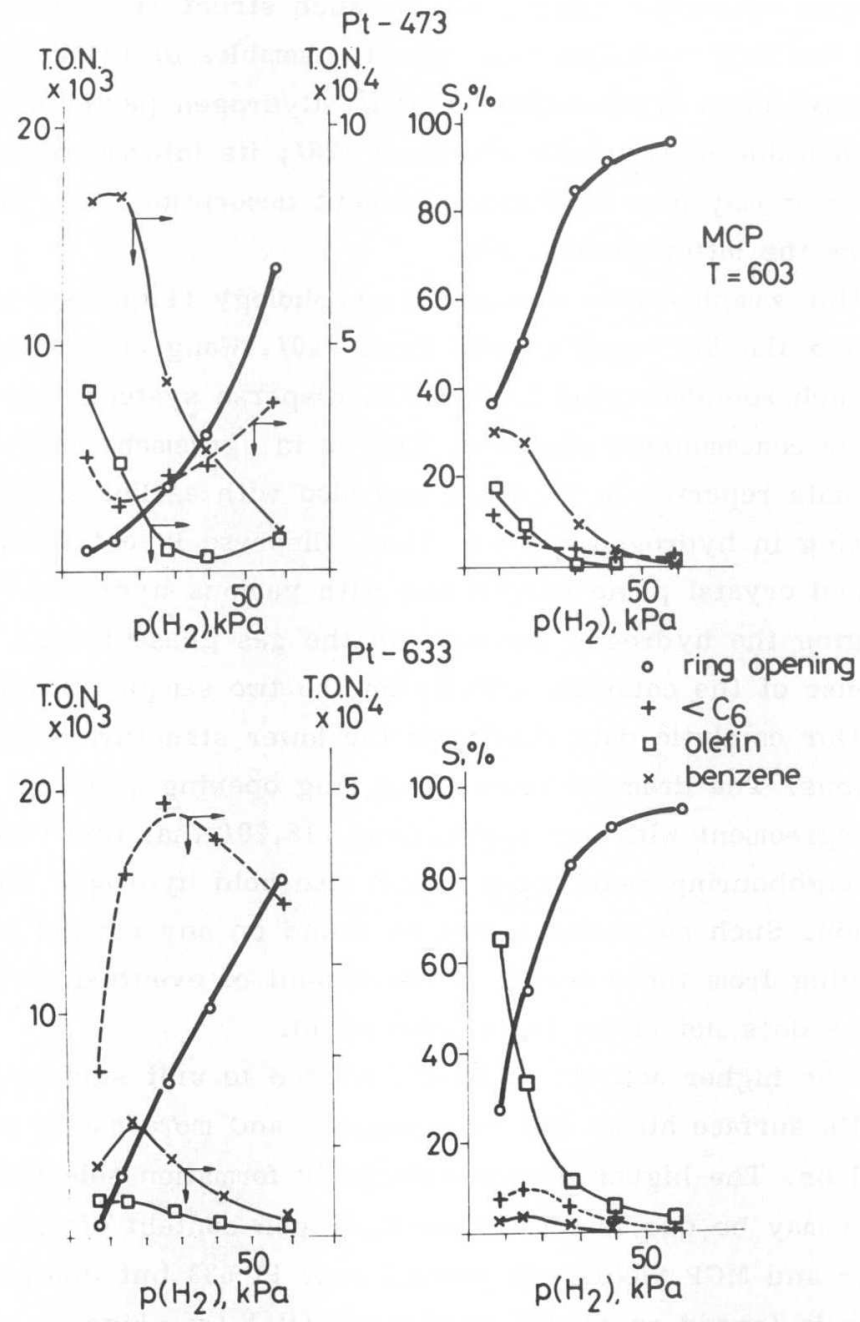

Figure 6. Activity and selectivity of $\mathrm{Pt}-473$ and $\mathrm{Pt}-633$ in methylcyclopentane transformations. $\mathrm{T}=603 \mathrm{~K}$. 


\section{Discussion}

Surface geometry, hydrogen availability and the eventual presence of impurities determine the actual catalytic properties of Pt. Single crystals with hexagonal symmetry - (111), (322) and $(10,8,7)$ faces were more active in $\mathrm{nH}$ aromatization than those with tetragonal - (100) - symmetry /13/. Five-coordinated $B_{5}$ sites were claimed to be active in hydrogenolysis /23/. Such structures also represent peculiar hydrogen adsorption sites /24/. No such structure-sensitivity was found for MCP reactions /23/. Small ensembles of 1-3 Pt-atoms were the active sites of aromatization $/ 25 /$. Hydrogen participates in the active ensemble of $\mathrm{C}_{5}$-cyclic reactions $/ 28 /$; its intermediates may desorb as MCP or may give isohexanes without desorption /26/. More hydrogen favours the latter process $/ 4 /$.

Our samples show a rounded morphology (Figures 2 and 3 ) not exposing flat low index crystal faces $/ 20 /$. Wang et al. suggested /27/ that such rounded crystal shapes in disperse systems may arise owing to their contaminated surfaces. This is in agreement with surface analysis data reported in Figure 1 and also with earlier studies $/ 14-16,19 /$. Sintering in hydrogen creates, thus, disperse Pt-catalysts with ill-defined crystal plane shapes and with various hydrogen content. Changing the hydrogen pressure in the gas phase brings about various response of the catalytic activity on the two samples studied.

Our catalytic data confirmed the lower structure-sensitivity of MCP reactions. The dramatic increase of ring opening yields at higher $\mathrm{p}\left(\mathrm{H}_{2}\right)$ is in agreement with our suggestions $/ 18,20 /$ that this reaction requires two neighbouring metal atoms which also hold hydrogen during the reaction. Such an ensemble can be found on any crystal plane and - judging from these results - the amount of eventual carbon on the surface does not affect these sites at all.

The higher activity of $\mathrm{Pt}-473$ related to unit surface indicates that its surface atoms are more exposed and more easily available for reactions. The higher isomerization/MCP formation selectivity over Pt-473 may be due to the higher hydrogen content of this catalyst $/ 16 /$. Isomer and MCP yields are parallel over Pt-633 but distinctly more isomer is formed on Pt-473 at higher $\mathrm{p}\left(\mathrm{H}_{2}\right)$ (cf. Figs. 4 and 5), that is the "hydrogen utilization" is better on the former sample /4,21/. 
This can be attributed to hydrogen retained and the facility of its interaction with the hydrocarbon reactant.

Both benzene and fragments require deeply dehydrogenated surface intermediates. Obviously, aromatization is favoured over Pt-473. With increasing $\mathrm{p}\left(\mathrm{H}_{2}\right)$, the competition between hydrogen and hydrocarbons first decreases aromatization activity; thereafter, however, a strong increase is seen (Fig. 5). Hydrogen must either be able to remove individual carbonaceous species blocking active sites or there must be a possibility that under these conditions "H-Pt-C" sites are created which are favourable for nondestructive reactions /28/. Pt single crystal faces with rather large carbon coverages have also been found to be active, the hydrogen attached to $\mathrm{C}$ being able to interact with hydrocarbon reactants $/ 29 /$.

A more prominent competition between hydrogen and hydrocarbons is observed over $\mathrm{Pt}-633$. Here the partly polymerized carbonaceous overlayer leaves free a fraction of the surface only for catalysis. Of all reactions, fragmentation seems to be least affected: its selectivity remains high, like in the case of partly coked $\mathrm{Pt} / \mathrm{SiO}_{2}$ catalyst $/ 21 /$ and $\mathrm{Pt}(111)$ single crystal face /29/. The presence of extra $\mathrm{B}_{5}$ -sites is not confirmed by our results.

\section{Acknowledgement}

The authors thank Dr. D. Marton for the SIMS measurements. The financial support was supplied by Grant OTKA 1309.

\section{References}

1. Bond G.C., Catalysis by Metals, New York, Acad. Press, 1962.

2. Pines H., The Chemistry of Catalytic Hydrocarbon Conversions, New York, Acad. Press, 1981.

3. Paál Z. and Menon P.G., Catal. Rev.-Sci. Eng. 25, 229 (1983).

4. Paál Z. and Menon P.G. (Editors), Hydrogen Effect in Catalysis, New York, Marcel Dekker, 1988.

5. Tsuchiya S., Amenomiya A. and Cvetanovic R., J. Catal. 19, 245 (1970).

6. Móger D., Besenyei G. and Nagy F., Magy. Kém. Folyóirat 81 , 284 (1975). 
7. Popova N.M., Babenkova L.V. and Savelyeva G.A., Adsorption and Interaction of the Simplest Gases with Group VIII Metals (in Russian) Alma-Ata, Nauka Kaz. SSR, 1979.

8. Frennet A. and Wells P.B., Appl. Catal. 18, 243 (1985).

9. Paál Z. and Thomson S.J., J. Catal. 30, 96 (1973).

10. Eley D.D. and Pearson J.F., J. Chem. Soc. Faraday Trans I, 74, 223 (1978).

11. Baird T., Paál Z. and Thomson S.J., J. Chem. Soc. Faraday Trans. 69,50 (1973); $\underline{69}, 1237$ (1973).

12. Manninger I., Paál Z. and Tétényi P., Z. phys. Chem. Neue Folge, 132, 193 (1982).

13. Davis S.M., Zaera F. and Somorjai G.A., J. Catal. 85, 206 (1985); Zaera F., Godbey D. and Somorjai G.A., J. Catal. 101, 73 (1986).

14. Paál Z., Tétényi P., Prigge D., Wang X.Zh. and Ertl G., Appl. Surface Sci. 14, 307 (1982-83).

15. Paál Z., Tétényi P., Kertész L., Szász A. and Kojnok J., Appl. Surface Sci. 14, 101 (1982-83).

16. Paál Z. and Marton D., Appl. Surface Sci. 26, 161 (1986).

17. Tétényi P. and Babernics L., Acta Chim. Acad. Sci. Hung. $\underline{35}$, 419 (1963).

18. Zimmer H., Paál Z. and Tétényi P., Acta Chim. Acad. Sci. Hung. 111,513 (1982).

19. Barna A., Barna P.B., Tóth L., Paál Z. and Tétényi P., Appl. Surface Sci. 14, 85 (1982-83).

20. Zimmer H., Dobrovolszky M., Tétényi P. and Paál Z., J. Phys. Chem. 90, 4758 (1986).

21. Paál Z., Zimmer H. and Tétényi P., J. Mol. Catal. 25, 99 (1984).

22. Paál Z., Groeneweg H. and Zimmer H., Catalysis Today, in press.

23. Dauscher A., Garin F. and Maire G., J. Catal. 105, 233 (1987).

24. Baró A.M. and Ibach H., Surf. Sci. 92, 237 (1980).

25. Biloen P., Helle J.N., Verbeek H., Dautzenberg F.M. and

Sachtler W.M.H., J. Catal. 63, 112 (1980).

26. Gault F.G., Adv. Catal. 30, 1 (1980).

27. Wang T., Lee C. and Schmidt L.D., Surf. Sci. 163, 181 (1985).

28. Sárkány A., J. Chem. Soc. Faraday Trans. I, 84, 2267 (1988).

29. Davis S.M., Zaera F. and Somorjai G.A., J. Catal. 77, 439 (1982). 